\title{
Possible anti-oxidative effects of long-term administration of Juzen-taiho-to in dogs
}

\author{
Yuta SHINOHARA ${ }^{1,2)}$, Ayaka OYAMA ${ }^{1)}$, Tatsuya USUI ${ }^{1)}$ and Kazuaki SASAKI ${ }^{1) *}$ \\ 1)Laboratory of Veterinary Pharmacology, Department of Veterinary Medicine, Faculty of Agriculture, \\ Tokyo University of Agriculture and Technology, 3-5-8 Saiwai-cho, Fuchu, Tokyo 183-8509, Japan \\ 2) Pet Health \& Food Division, Iskara Industry Co., Ltd., 1-14-2, Nihonbashi, Chuo-ku, Tokyo 103-0027, Japan
}

\section{J. Vet. Med. Sci. \\ 81(11): 1616-1620, 2019}

doi: 10.1292/jvms.19-0380

Received: 10 July 2019

Accepted: 13 September 2019

Advanced Epub:

4 October 2019

\begin{abstract}
It is known that oxidative stress is related to disease in humans and dogs. Many traditional Chinese medicines have been reported to have anti-oxidative effects, but there are no reports that they have anti-oxidative effects in dogs. In this study, we examined the anti-oxidative effects of Juzen-taiho-to, a traditional Chinese medicine, in dogs. Five healthy female beagle dogs (38-41 months of age weighing 8.6-10.7 kg) were orally administered Juzen-taiho-to at $450 \mathrm{mg} /$ $\mathrm{kg}$ with food for 28 days. Blood samples were taken from all five dogs on days $0,7,14,21$, and 28. Using the blood samples, improvement of the antioxidant level as assessed by the biological antioxidant potential (BAP), reduced oxidative stress level as assessed by derivatives of reactive oxygen metabolites (d-ROMs), and improvement of blood fluidity were examined. Regarding the antioxidant level and blood fluidity, no significant difference was observed, but the oxidative stress level on days 14,21 , and 28 was significantly lower than that on day 0 . Thus, Juzen-taiho-to may have anti-oxidative effects in dogs by reducing oxidative stress and be useful for oxidative stress-related diseases in dogs.
\end{abstract}

KEY WORDS: anti-oxidative effect, dog, Juzen-taiho-to, traditional Chinese medicine

Oxidative stress is known to be related to many diseases in humans. For example, oxidative stress was increased during carcinogenesis in prostate cancer patients [8]. Oxidative stress has also been implicated in cardiovascular diseases (CVD). Wang et al. reported a correlative relationship between the blood concentration of myeloperoxidase, a well-characterized source of oxidative stress, and the incidence of CVD [20]. In a previous cohort study, the oxidative stress level in serum was found to be highly associated with cancer mortality and CVD [12].

A relationship between oxidative stress and diseases has also been reported in dogs. Malondialdehyde (MDA), the end product of lipid peroxidation, is commonly used as a marker of oxidative stress. The serum concentration of MDA was significantly higher in cancer-bearing dogs than in clinically normal dogs [9]. In addition, antioxidants reduced the incidence of arrhythmias in dogs [2]. Although these studies noted a relationship between oxidative stress and disease in dogs, anti-oxidative therapy for dogs has not been developed.

Many traditional Chinese medicines have been reported to possess anti-oxidative properties and are used for oxidative stressrelated diseases in humans [3]. Traditional Chinese medicines have been reported to prevent ischemic heart disease through the inhibition of oxidative stress [19]. Furthermore, recent studies have clarified which components of traditional Chinese medicines have anti-oxidative effects [1]. However, there are no reports on the anti-oxidative effects of traditional Chinese medicines in diseased or healthy dogs.

Juzen-taiho-to contains ten crude drugs, such as Panax ginseng and Angelica acutiloba, and was traditionally used to treat fatigue and anorexia. Administration of Juzen-taiho-to to mice reduced the amount of oxidants in the liver [17].

Although traditional Chinese medicines have been reported to have anti-oxidative effects in humans [3], it remains unclear whether Juzen-taiho-to affects oxidative stress-induced dog diseases. In the present study, we therefore examined whether long-term administration of Juzen-taiho-to improves the anti-oxidant level and reduces the oxidative stress level in dogs. As antioxidative effects were reported to be related to blood fluidity, this was also investigated [10].

\section{MATERIALS AND METHODS}

\section{Animals}

Five healthy female beagle dogs (38-41 months of age weighing 8.6-10.7 kg) were obtained from the Research Institute for 
Animal Science in Biochemistry and Toxicology (Tokyo, Japan). An acclimatization period was given for one month. They were housed individually in stainless-steel cages under a controlled environment. Commercial dried pellet diet and canned dog food were given at a fixed time each day. Water was given ad libitum. Animals were cared for following the recommendations of the 'Guide for the Care and Use of Laboratory Animals' approved by the Faculty of Agriculture, Tokyo University of Agriculture and Technology.

\section{Chemicals and reagents}

Juzen-taiho-to was obtained from TSUMURA (Tokyo, Japan). Heparin sodium was obtained from Mochida Pharmaceutical Co., Ltd. (Tokyo, Japan).

\section{Experimental design}

Dogs were orally administered Juzen-taiho-to at $450 \mathrm{mg} / \mathrm{kg}$ with food for 28 days. This dose was calculated based on Juzentaiho-to use for humans. Blood samples were taken from the cephalic vein of all five dogs with heparinization on days $0,7,14$, 21, and 28 (Fig. 1). Using the blood samples, the antioxidant level, oxidative stress level, and blood fluidity were measured by an automated method.

\section{Assessment of the antioxidant level}

In this study, the antioxidant level was assessed by the biological antioxidant potential (BAP) test using an automatic analyzer FREE Carrio Duo (WISMERLL Co., Ltd., Tokyo, Japan). The BAP test is a simple photometric assay that measures the concentration of total antioxidants by their capacity to reduce iron from the ferric to the ferrous form. First, $0.2 \mathrm{~m} l$ of blood was collected from the cephalic vein of all five dogs with heparinization. Next, heparinized plasma samples were obtained by blood centrifugation at 1,200 $\mathrm{g} \times 2 \mathrm{~min}$. Plasma samples were mixed with a colored solution, obtained by mixing a ferric chloride solution with a thiocyanate derivative solution, which causes discoloration. The intensity was measured photometrically at $505 \mathrm{~nm}$ and was proportional to the ability of the plasma to reduce ferric ions (Table 1). The results are expressed as mM of reduced ferric ions.

\section{Assessment of the oxidative stress level}

The oxidative stress level was assessed by the derivatives of reactive oxygen metabolites (d-ROMs) test using an automatic analyzer FREE Carrio Duo. d-ROM levels are a proxy for reactive oxygen species (ROS) production [12]. First, $0.2 \mathrm{~m} l$ of blood was collected from the cephalic vein of all five dogs with heparinization. Next, heparinized plasma samples were obtained by blood centrifugation at 1,200 $\mathrm{g} \times 2 \mathrm{~min}$. In the d-ROMs test, hydroperoxides in the plasma are released from plasma proteins by an acidic buffer in the presence of iron $\left(\mathrm{Fe}^{2+}\right.$ and $\left.\mathrm{Fe}^{3+}\right)$, and generate alkoxyl and peroxyl radicals according to the Fenton reaction. Such radicals then oxidize an alkyl-substituted aromatic amine (N, N-dietylparaphenylendiamine), thereby producing a pink-colored derivative, which is photometrically quantified at $505 \mathrm{~nm}$. The d-ROM concentration is directly proportional to the color intensity and is expressed as U.CARR (Carratelli Units). One U.CARR corresponds to $0.8 \mathrm{mg} / \mathrm{l}$ hydrogen peroxide [13]. After Juzen-taihoto was administered to all five dogs at the concentration of $450 \mathrm{mg} / \mathrm{kg}$, blood samples were collected and the d-ROMs test was conducted every week (Fig. 1). In the previous study, the normal range in healthy dogs was from 59.4 to 91.4 U.CARR [11].

\section{Assessment of blood fluidity}

After Juzen-taiho-to was administered to all five dogs at the concentration of $450 \mathrm{mg} / \mathrm{kg}$, blood samples were collected and the time was evaluated every week (Fig. 1). Approximately $1.5 \mathrm{~m} l$ of blood was collected from the cephalic vein of all five dogs at 14:00 and blood fluidity was evaluated within $10 \mathrm{~min}$ after blood sampling by measuring the blood passage time using the MCFAN (MC Healthcare Inc., Tokyo, Japan) automatically. In MCFAN, there is a microchannel array (width: $7 \mu \mathrm{m})$ and the blood passage time was measured based on the passage time of the channel. In more detail, the microchannel passage time of $100 \mu l$ of physiological saline was first measured as a control, and then that of the blood samples obtained from the subjects was measured. The blood passage time was expressed after correction using the passage time of physiological saline. With this system, the blood passage time can be measured within $180 \mathrm{sec}$ and subjects with a blood passage time longer than $180 \mathrm{sec}$ were excluded.

\section{Statistical analysis}

Welch's $t$-test was used to analyze the significant differences in the BAP test, d-ROMs test, and blood passage time between the values on day 0 and those on days 14, 21, and 28. Then, the Holm method was used. Significance between groups was accepted when $P<0.05$.

\section{RESULTS}

\section{Effects of long-term administration of Juzen-taiho-to on blood antioxidant level in dogs}

We first performed the BAP test to measure the blood antioxidant level. After Juzen-taiho-to was administered to five dogs at the concentration of $450 \mathrm{mg} / \mathrm{kg}$, blood samples were collected and the BAP test was conducted every week (Fig. 1). Before this experiment, we estimated BAP test for 28 days without Juzen-taiho-to but there was no change in the BAP values. The values by the BAP test remained unchanged in the present study (Table 1). In this study, food intake and body weight in dogs also remained unchanged (data not shown). 


\section{Effects of long-term administration of Juzen-taiho-to on the blood oxidative stress level in dogs}

We next performed the d-ROMs test to evaluate the effects of Juzen- taiho-to on oxidative stress. In the present study, the value in each dog before administration ranged from 77 to 87 U.CARR, suggesting that the dogs used in this experiment had normal oxidative stress levels [11]. Before this experiment, we estimated d-ROMs test for 28 days without Juzen-taiho-to but there was no change in the d-ROMs test values. The values by the d-ROMs test on days 14,21 , and 28 were significantly lower than that on day 0 , suggesting that Juzen-taiho-to reduced the blood oxidative stress level in dogs (Table 1).

\section{Effects of long-term administration of Juzen-taiho-to on blood fluidity in dogs}

As blood fluidity is known to be regulated by oxidative stress [14], we investigated whether Juzen-taiho-to affects this parameter in dogs. As an indicator of blood fluidity, we measured the microchannel passage time of blood (Table 1). Before this experiment, we estimated blood fluidity for 28 days without Juzen-taiho-to but there was no change in the microchannel passage time. In the present study, the time remained unchanged (Table 1).

\section{DISCUSSION}

To assess the anti-oxidative effects of Juzen-taiho-to in dogs, we orally administered it for 28 days, and examined improvement of the antioxidant level, oxidative stress level, and blood fluidity.

The antioxidant level in blood was assessed by the BAP test, which measures antioxidants as agents that can reduce iron from the ferric $\left(\mathrm{Fe}^{+}\right)$to ferrous form $\left(\mathrm{Fe}^{+}\right)$. The relationship between oxidative stress and diseases is well known in humans and dogs. If the antioxidant level is low, oxidative stress negatively affects the body because it is not protected from oxidative stress. In a previous human study, a low estimated glomerular filtration rate and high albuminuria were utilized to diagnose chronic kidney disease, and were positively correlated with low BAP values [4].

In the present study, the value in each dog before administration ranged from 1,561 to $1,873 \mathrm{mM}$, suggesting that the dogs used in this experiment had normal antioxidant levels [11]. The values by the BAP test remained unchanged in the present study (Table 1). Sechi et al. previously reported that administration of an antioxidant dietary supplement that contained polyphenols to dogs improved d-ROM values but not BAP values [13].

Juzen-taiho-to contains ten crude drugs, almost all of which include polyphenol [7, 16]. Although polyphenol is one of the materials that influences BAP values, the amount contained in Juzen-taiho-to may be insufficient to improve BAP values in dogs.

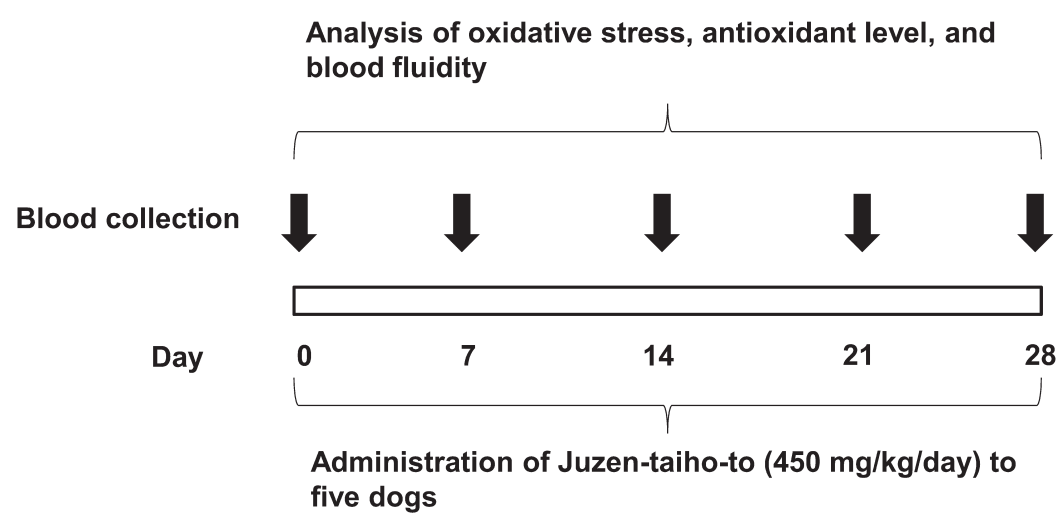

Fig. 1. Schematic experimental design of the time course of Juzen-taiho-to administration to dogs and blood collection. After Juzen-taiho-to was administered to five dogs at the concentration of $450 \mathrm{mg} / \mathrm{kg}$ every day, each blood sample was collected on days $0,7,14,21$, and 28 to analyze the antioxidant level, oxidative stress level, and blood fluidity.

Table 1. Average antioxidant level, oxidative stress level, and blood flow time on Days $0,7,14,21$, and 28

\begin{tabular}{llcc}
\hline & $\begin{array}{c}\text { BAP }(\mathrm{mM}) \\
\text { Mean } \pm \text { S.D. }\end{array}$ & $\begin{array}{c}\text { d-ROMs }(\text { U.CARR) } \\
\text { Mean } \pm \text { S.D. }\end{array}$ & $\begin{array}{c}\text { Flow time }(\mathrm{sec}) \\
\text { Mean } \pm \text { S.D. }\end{array}$ \\
\hline Day 0 & $1,705.8 \pm 101.8$ & $81.8 \pm 3.5$ & $40.38 \pm 5.0$ \\
Day 7 & $1,607.4 \pm 72.8$ & $82.2 \pm 4.3$ & $39.58 \pm 9.3$ \\
Day 14 & $1,756.8 \pm 216.6$ & $75.3 \pm 2.4^{\text {a) }}$ & $37.08 \pm 4.2$ \\
Day 21 & $1,750.0 \pm 142.7$ & $71.8 \pm 5.3$ a) & $34.38 \pm 2.5$ \\
Day 28 & $1,697.6 \pm 127.1$ & $68.2 \pm 7.1$ a) & $37.16 \pm 5.4$ \\
\hline
\end{tabular}

a) $P<0.05$ vs. Day 0. U.CARR: Carratelli Units. 
The oxidative stress level was assessed by the d-ROMs test. The concentration of d-ROMs was used as an index of the production of ROS, with high values indicating higher oxidative stress. Many studies have demonstrated the mechanism by which ROS stress can lead to chronic inflammation and chronic diseases, including cardiovascular diseases, neurological diseases, pulmonary diseases, diabetes, and cancers [3]. For example, ROS are associated with the development and progression of many types of cancers in dogs [9]. As shown in Table 1, administration of Juzen-taiho-to to dogs significantly reduced oxidative stress levels in the blood in our study. The degree of that effect of Juzen-taiho-to was almost same as that of other traditional Chinese medicines such as Toki-syakuyakusan, Saiko-ka-ryukotsu-borei-to, Tokaku-jokito and Keishi-bukuryo-gan in rats [5]. Ginseng is a popular tonic for many diseases and included in Juzen-taiho-to. The ethyl acetate extract from ginseng and its main constituents inhibited ROS generation and increased superoxide dismutase activity in mouse cells [6]. It was also reported that glycyrrhizic acid and 18ß-glycyrrhetinic acid from licorice, which is also included in Juzen-taiho-to, significantly inhibit the production of ROS in mouse monocyte macrophages [18]. Moreover, intraperitoneal injection of Juzen-taiho-to increased hepatic metallothionein levels in mice [21]. Metallothionein has antioxidant properties against ROS and free radical scavenging abilities. Considering these reports, it is likely that the administration of Juzen-taiho-to to dogs reduced the oxidative stress levels by inhibiting the production of ROS in cells and increasing hepatic metallothionein levels. In the study that estimated the anti-oxidative effects of anti-oxidative supplement composed of Grifola frondosa, Curcuma longa and so on in dogs, it took 6 months for the supplement to express the anti-oxidative effects [13]. Considering these thing, expression of the anti-oxidative effects may need certain time in dogs. Because Juzen-taiho-to expressed the anti-oxidative effects in 14 days, Juzen-taiho-to may express the anti-oxidative effects relatively faster but 7 days might be short to expressed the anti-oxidative effects.

The reduction of blood fluidity is considered to be related to numerous diseases such as cardiovascular disease [15]. Although it is controlled by several factors, anti-oxidative effects were reported to be related to blood fluidity. For example, astaxanthin, which has anti-oxidative effects, improved blood fluidity by reducing the blood passage time measured by MCFAN [10]. Improvement of blood fluidity is associated with the anti-oxidative effects of maintaining the flexibility of the erythrocyte membrane [10]. As shown in Table 1, the blood passage time was unchanged in our study. Considering the d-ROMs test, Juzen-taiho-to may reduce oxidative stress, but its effects were insufficient to improve blood fluidity.

In conclusion, long-term administration of Juzen-taiho-to reduced the oxidative stress level in blood in dogs, and may therefore be useful for oxidative stress-related diseases in dogs.

ACKNOWLEDGMENT. The authors would like to thank Dr. Minoru Shimoda for useful advice for this research.

\section{REFERENCES}

1. Chen, C. Y., Li, H., Yuan, Y. N., Dai, H. Q. and Yang, B. 2013. Antioxidant activity and components of a traditional Chinese medicine formula consisting of Crataegus pinnatifida and Salvia miltiorrhiza. BMC Complement. Altern. Med. 13: 99. [Medline] [CrossRef]

2. Downey, J. M., Omar, B., Ooiwa, H. and McCord, J. 1991. Superoxide dismutase therapy for myocardial ischemia. Free Radic. Res. Commun. 12-13: 703-720. [Medline] [CrossRef]

3. He, Y., Yue, Y., Zheng, X., Zhang, K., Chen, S. and Du, Z. 2015. Curcumin, inflammation, and chronic diseases: how are they linked? Molecules 20: 9183-9213. [Medline] [CrossRef]

4. Ishizaka, Y., Yamakado, M., Toda, A., Tani, M. and Ishizaka, N. 2013. Relationship between estimated glomerular filtration rate, albuminuria, and oxidant status in the Japanese population. BMC Nephrol. 14: 191. [Medline] [CrossRef]

5. Ishikawa, S., Kubo, T., Sunagawa, M., Tawaratsumita, Y., Sato, T., Ishino, S. and Hisamitsu, T. 2011. Influence of Chinese herbal medicine on reactive oxygen and blood fluidity in rats. Kampo Med 62: 337-346 (in Japanese). [CrossRef]

6. Jiang, R., Xu, X. H., Wang, K., Yang, X. Z., Bi, Y. F., Yan, Y., Liu, J. Z., Chen, X. N., Wang, Z. Z., Guo, X. L., Zhao, D. Q. and Sun, L. W. 2017. Ethyl acetate extract from Panax ginseng C.A. Meyer and its main constituents inhibit $\alpha$-melanocyte-stimulating hormone-induced melanogenesis by suppressing oxidative stress in B16 mouse melanoma cells. J. Ethnopharmacol. 208: 149-156. [Medline] [CrossRef]

7. Kim, J. 2008. Protective effects of Asian dietary items on cancers - soy and ginseng. Asian Pac. J. Cancer Prev. 9: 543-548. [Medline]

8. Kurfurstova, D., Bartkova, J., Vrtel, R., Mickova, A., Burdova, A., Majera, D., Mistrik, M., Kral, M., Santer, F. R., Bouchal, J. and Bartek, J. 2016. DNA damage signalling barrier, oxidative stress and treatment-relevant DNA repair factor alterations during progression of human prostate cancer. Mol. Oncol. 10: 879-894. [Medline] [CrossRef]

9. Macotpet, A., Suksawat, F., Sukon, P., Pimpakdee, K., Pattarapanwichien, E., Tangrassameeprasert, R. and Boonsiri, P. 2013. Oxidative stress in cancer-bearing dogs assessed by measuring serum malondialdehyde. BMC Vet. Res. 9: 101. [Medline] [CrossRef]

10. Miyawaki, H., Takahashi, J., Tsukahara, H. and Takehara, I. 2008. Effects of astaxanthin on human blood rheology. J. Clin. Biochem. Nutr. 43: 69-74. [Medline] [CrossRef]

11. Pasquini, A., Luchetti, E., Marchetti, V., Cardini, G. and Iorio, E. L. 2008. Analytical performances of d-ROMs test and BAP test in canine plasma. Definition of the normal range in healthy Labrador dogs. Vet. Res. Commun. 32: 137-143. [Medline] [CrossRef]

12. Schöttker, B., Brenner, H., Jansen, E. H., Gardiner, J., Peasey, A., Kubínová, R., Pająk, A., Topor-Madry, R., Tamosiunas, A., Saum, K. U., Holleczek, B., Pikhart, H. and Bobak, M. 2015. Evidence for the free radical/oxidative stress theory of ageing from the CHANCES consortium: a meta-analysis of individual participant data. BMC Med. 13: 300. [Medline] [CrossRef]

13. Sechi, S., Chiavolelli, F., Spissu, N., Di Cerbo, A., Canello, S., Guidetti, G., Fiore, F. and Cocco, R. 2015. An antioxidant dietary supplement improves brain-derived neurotrophic factor levels in serum of aged dogs: preliminary results. J. Vet. Med. 2015: 412501. [Medline] [CrossRef]

14. Simmonds, M. J., Meiselman, H. J. and Baskurt, O. K. 2013. Blood rheology and aging. J. Geriatr. Cardiol. 10: 291-301. [Medline]

15. Sloop, G. D., Weidman, J. J. and St Cyr, J. A. 2018. Perspective: interesterified triglycerides, the recent increase in deaths from heart disease, and elevated blood viscosity. Ther. Adv. Cardiovasc. Dis. 12: 23-28. [Medline] [CrossRef]

16. Song, N. R., Kim, J. E., Park, J. S., Kim, J. R., Kang, H., Lee, E., Kang, Y. G., Son, J. E., Seo, S. G., Heo, Y. S. and Lee, K. W. 2015. Licochalcone A, a polyphenol present in licorice, suppresses UV-induced COX-2 expression by targeting PI3K, MEK1, and B-Raf. Int. J. Mol. Sci. 16: 
4453-4470. [Medline] [CrossRef]

17. Tsuchiya, M., Kono, H., Matsuda, M., Fujii, H. and Rusyn, I. 2008. Protective effect of Juzen-taiho-to on hepatocarcinogenesis is mediated through the inhibition of Kupffer cell-induced oxidative stress. Int. J. Cancer 123: 2503-2511. [Medline] [CrossRef]

18. Wang, C. Y., Kao, T. C., Lo, W. H. and Yen, G. C. 2011. Glycyrrhizic acid and 18ß-glycyrrhetinic acid modulate lipopolysaccharide-induced

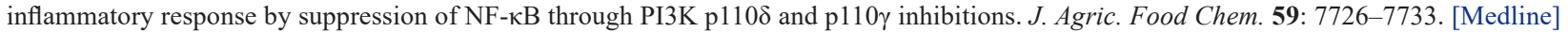
[CrossRef]

19. Wang, D., Wang, J., Liu, Y., Zhao, Z. and Liu, Q. 2016. Roles of Chinese herbal medicines in ischemic heart diseases (IHD) by regulating oxidative stress. Int. J. Cardiol. 220: 314-319. [Medline] [CrossRef]

20. Wang, G., Mathew, A. V., Yu, H., Li, L., He, L., Gao, W., Liu, X., Guo, Y., Byun, J., Zhang, J., Chen, Y. E. and Pennathur, S. 2018. Myeloperoxidase mediated HDL oxidation and HDL proteome changes do not contribute to dysfunctional HDL in Chinese subjects with coronary artery disease. PLoS One 13: e0193782. [Medline] [CrossRef]

21. Yoshioka, H., Fukaya, S., Miura, N., Onosaka, S., Nonogaki, T. and Nagatsu, A. 2016. Suppressive effect of Kampo formula "Juzen-taiho-to" on carbon tetrachloride-induced hepatotoxicity in mice. Biol. Pharm. Bull. 39: 1564-1567. [Medline] [CrossRef] 